\section{A Survey of Gold Intermetallic Chemistry}

\author{
R. Ferro, A. Saccone, D. Macciò, S. Delfino \\ Dipartimento di Chimica e Chimica Industriale, \\ Università di Genova, via Dodecaneso 31, \\ I-16146 Genova (Italy)
}

The general alloying behaviour of gold is summarized on the basis of the literature data and the experimental results obtained by the authors on specific groups of gold alloys. Crystallochemistry, phase equilibria and diagrams, thermodynamic properties are especially considered. These properties and their trends are discussed with reference to the position in the Periodic Table of the metal partner of the gold alloys.
The alloying behaviour of gold with its intermetallic chemistry has its own particular characteristics, which are important both as a sound basis for further study and for a great variety of applications (electronics and electrical engineering, coins and medals, jewelry, soldering, pen nibs, dental materials, coatings, etc.). General references to these aspects are given, for instance, in text books such as $(1,2,3)$ and in several papers published on specific scientific journals as the Cold Bulletin. References mainly to phase equilibria and structures are reported in compilations such as $(4,5,6,7,8)$.

A large number of binary, ternary and more complex gold alloys are known. In this short review, as a simple approach to the characteristics of the gold alloying behaviour, binary alloys only will be considered, with particular attention to the formation of intermediate phases (intermetallic compounds), their crystal structures and equilibria.

\section{Gold binary phase diagrams}

Firstly we may remark that it is possible to correlate some specific aspects of the phase diagrams (formation of solid solutions, intermediate compounds, etc.) to a number of elemental atomic parameters, generally showing a gradual variation along the Periodic Table, such as valence electron

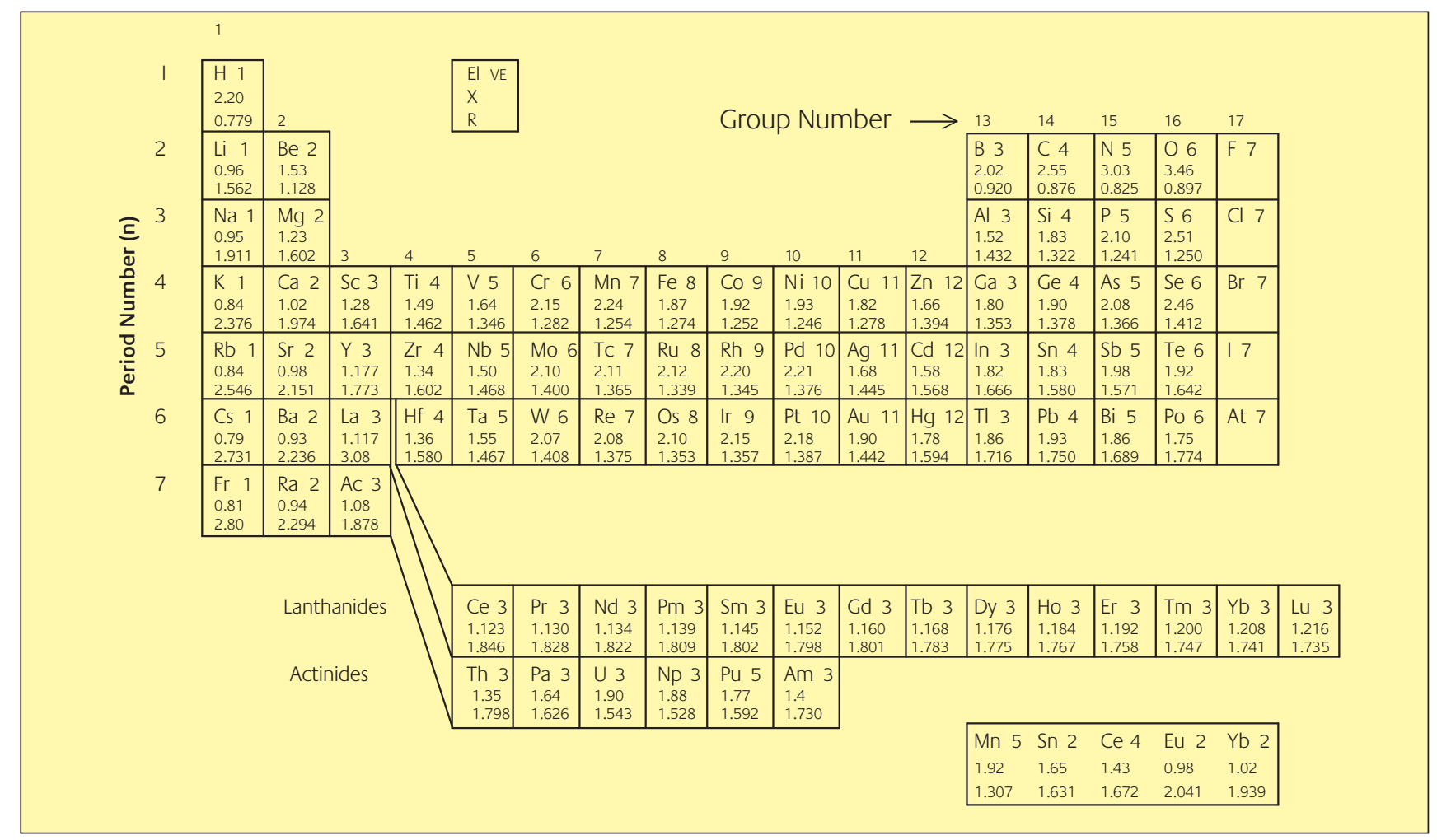

Figure 1

Periodic Table of the elements: the elements are arranged in the increasing order of their atomic numbers (not reported in the Table). The group and period numbers are shown. For each element Valence Electron Number (VE), Electronegativity (X) and Radius (R) at CN12 are reported (12) At the bottom right corner, for a few elements other valence states are given 

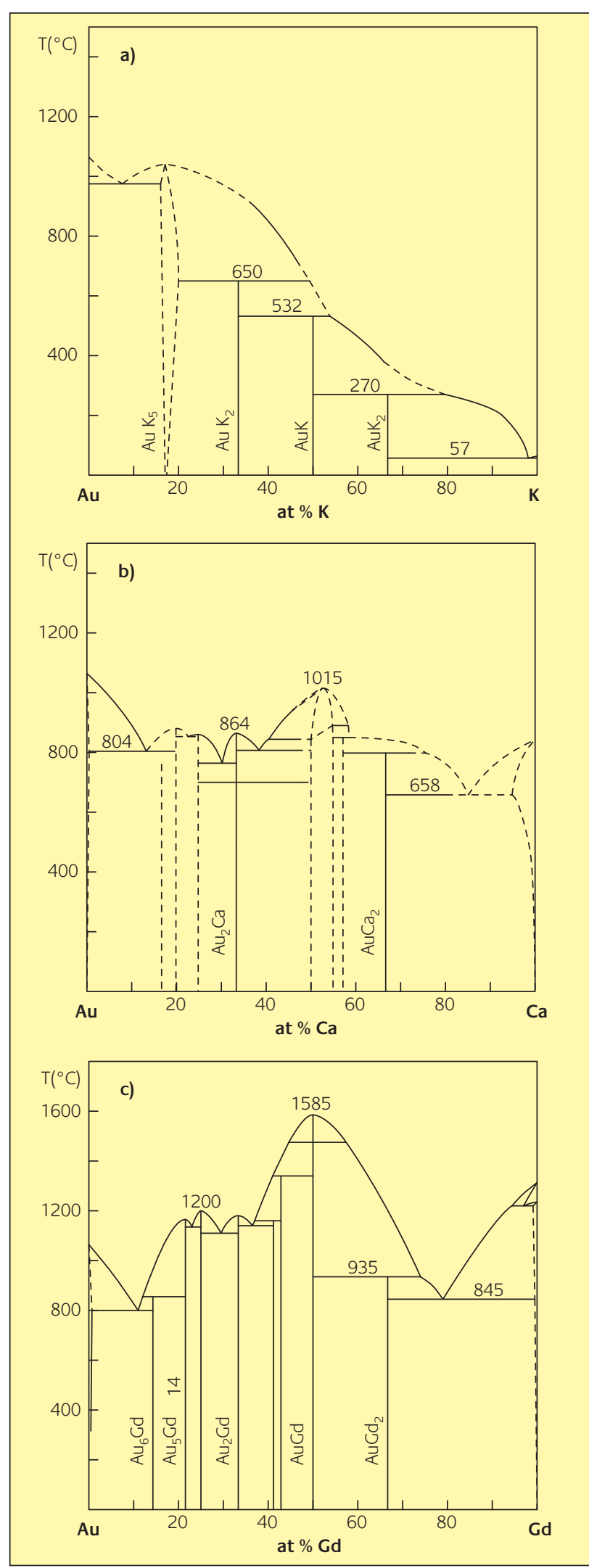

Figure 2

Phase diagrams of typical gold binary systems with elements of the 1st to 3rd group of the Periodic Table. a) Au-K phase diagram; b) Au-Ca phase diagram; c) Au-Gd phase diagram number (Periodic Table group number), electronegativity, atomic (and ionic) radius, Mendeleev number or elemental data such as melting and boiling point, sublimation heat, atomic volume, etc. (For a general discussion on this aspect see for instance refs. $(9,10)$ and databases such as "Pauling File" (11)). A few of the most important parameters are collected in Fig. 1.

With reference to these parameters and mainly to the position in the Periodic Table (see Fig.1) a short description will be given of the various binary gold-systems. In a somewhat arbitrary way these will be grouped in a few sets, starting from the left side of the Periodic Table.

\section{-Au alloys with the elements of the 1 st to 4 th groups}

A first type of gold binary phase diagrams is that given by the elements of the first groups (1st to 4th) of the Periodic Table. Within these elements the so-called rare earth metals ( $R=S c, Y$, and lanthanides) are included. Their reactivity with gold is very high, resulting in the formation of several stable compounds. These diagrams, exemplified in Fig.2 are generally characterized by the formation of several (from 3 to 8) compounds (generally point compounds or stoichiometric compounds, that is, having a small or very small range of homogeneity), often congruently melting and with high melting points. The thermal stability of these compounds may be related to the clearly exothermic formation characteristics (and the large electronegativity difference of these metals with respect to gold).

Special attention has been dedicated in the authors' laboratory to this group of alloys. Several $\mathrm{R}-\mathrm{Au}$ ( $\mathrm{R}=$ rare earth metal) phase diagrams have been experimentally studied (see, for instance, refs $(13,14,15)$ and heats of formation of some intermediate phases measured (16). Evidence has been especially given to the regular trends observed in the properties of the R-Au alloys on passing from one rare earth to the other. It has been shown that such regularities may be useful in predicting and designing alloying behaviour, as shown in several groups of rare earth alloys (see, for instance, refs $(17,18,19)$. Analogous comments have been presented in a recent paper by Ning (20) in which strenghtening of gold via rare earth metal additions has also been described.

Fig. 3 presents the trend of the enthalpy of formation of the gold alloys. In this figure for all the elements (identified by their position in the Periodic Table) the calculated heats of formation $\left(\triangle_{H} H\right)$ for the equiatomic composition are reported. These values have been obtained by using the wellknown semi-empirical formula by Miedema (21). The enthalpy of formation of solid binary alloys was described as proportional to the expression:

$$
\mathrm{f}\left[-\mathrm{P}\left(\Delta \phi^{*}\right)^{2}+\mathrm{Q}\left(\Delta \mathrm{n}_{\mathrm{ws}}{ }^{1 / 3}\right)^{2}-\mathrm{R}\right]
$$

where $f$ is a concentration (and molar volume) dependent function, $\Delta \phi^{*}=\phi_{A}{ }^{*}-\phi_{B}{ }^{*}$ where $\phi_{i}{ }^{*}$ is the work function of each 
element, closely related to its electronegativity, $n_{w s}$ is the electron density at the boundary of the Wigner-Seitz cell of each element, and P, Q and R are constants for specific groups of elements (their values depending on the position in the Periodic Table of the elements involved). Only a few experimental values are available (however, often not for the same composition). These are shown in the same Fig. 3 and they may give an indication of the reliability of the computed values.

The stability of the gold alloys with the elements of the first groups of the Periodic Table is evidenced by the strongly negative values of $\Delta_{H} \mathrm{H}$, with a minimum in the 3rd4th groups. The alloys are characterised by strong interactions not only in the solid state but also in the liquid state (these systems show a complete miscibility in this state). The Cs-Au system can be considered an extreme case among these alloys. Liquid Cs-Au alloys possess unusual physical and chemical properties, important in understanding the phase diagram. At 50 at\% Cs, liquid AuCs behaves as an ionic liquid (a molten salt consisting of $\mathrm{Cs}^{+}$and $\mathrm{Au}^{-}$ions) (22).

The Ti group element alloys play an intermediate role between this and the next set of diagrams.

\section{Table 1}

Maximum values of the so-called Raynor's index (23) (thermal stability of the intermediate phases) observed in systems formed by Au with the 4th period elements (see text)

\begin{tabular}{cc} 
System & Raynor index \\
\hline K-Au & $>1(1.12)$ \\
\hline Ca-Au & $>1(1.05)$ \\
\hline Sc-Au & $>1(1.25)$ \\
\hline Ti-Au & $>1(1.08)$ \\
\hline V-Au & $\approx 1$ \\
\hline Cr-Au & $<1$ \\
\hline Mn-Au & $>1(1.07)$ \\
\hline Fe-Au & $<1$ \\
\hline Co-Au & $<1$ \\
\hline Ni-Au & $<1$ \\
\hline Cu-Au & $<1$ \\
\hline Zn-Au & $\approx 1$ \\
\hline
\end{tabular}

-Au alloys with the elements of the 5 th to 9 th groups Examples of the corresponding phase diagrams of these alloys are reported in Fig. 4.

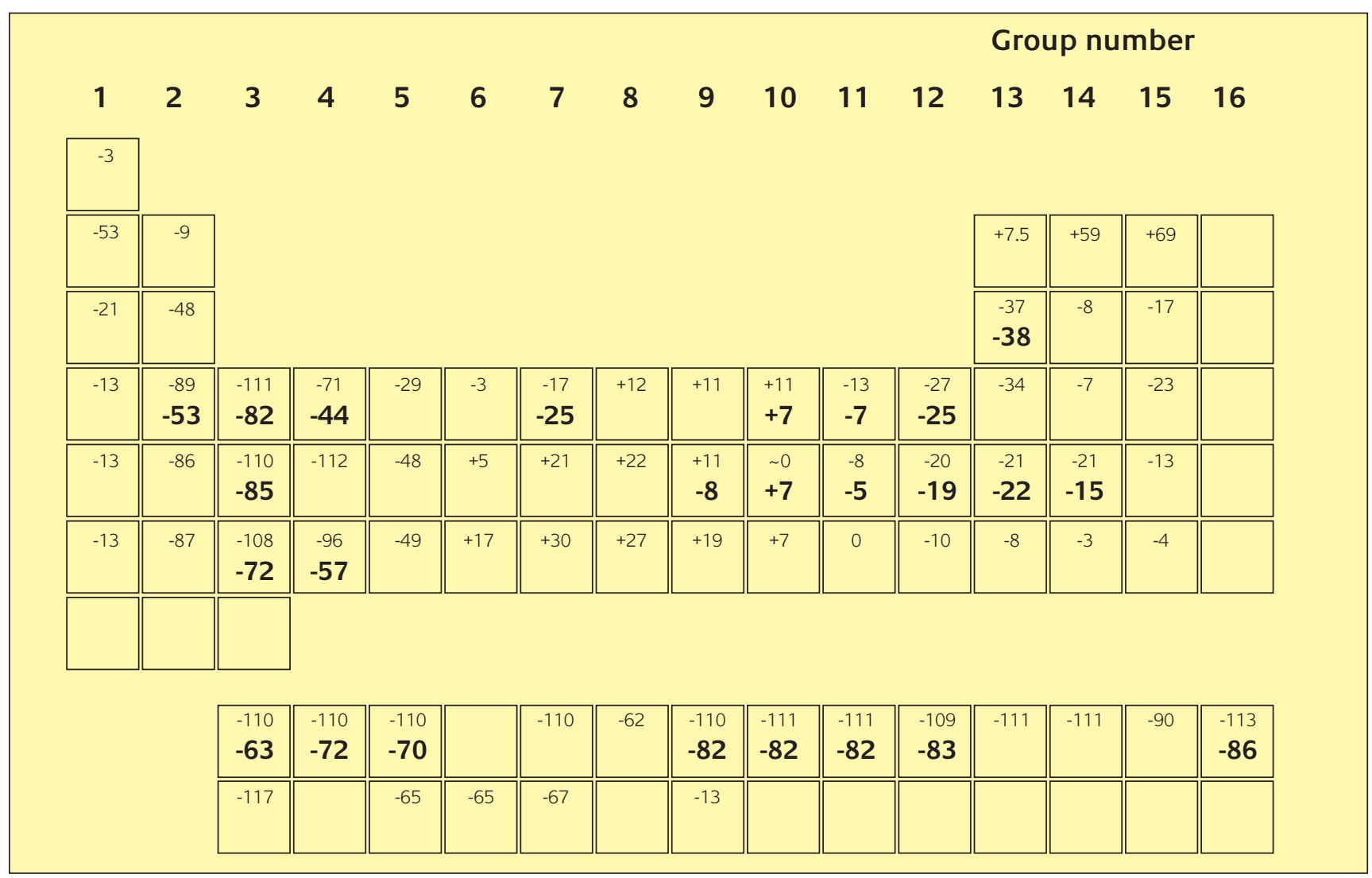

Figure 3

$\triangle H$ of formation of solid Au-alloys, ordered according to the position of the partner in the Periodic table. Values computed according to Miedema (21) for the Au-El system equiatomic composition are given. For a few elements the experimental values relevant to the most exothermic composition are also shown (in bold characters) 

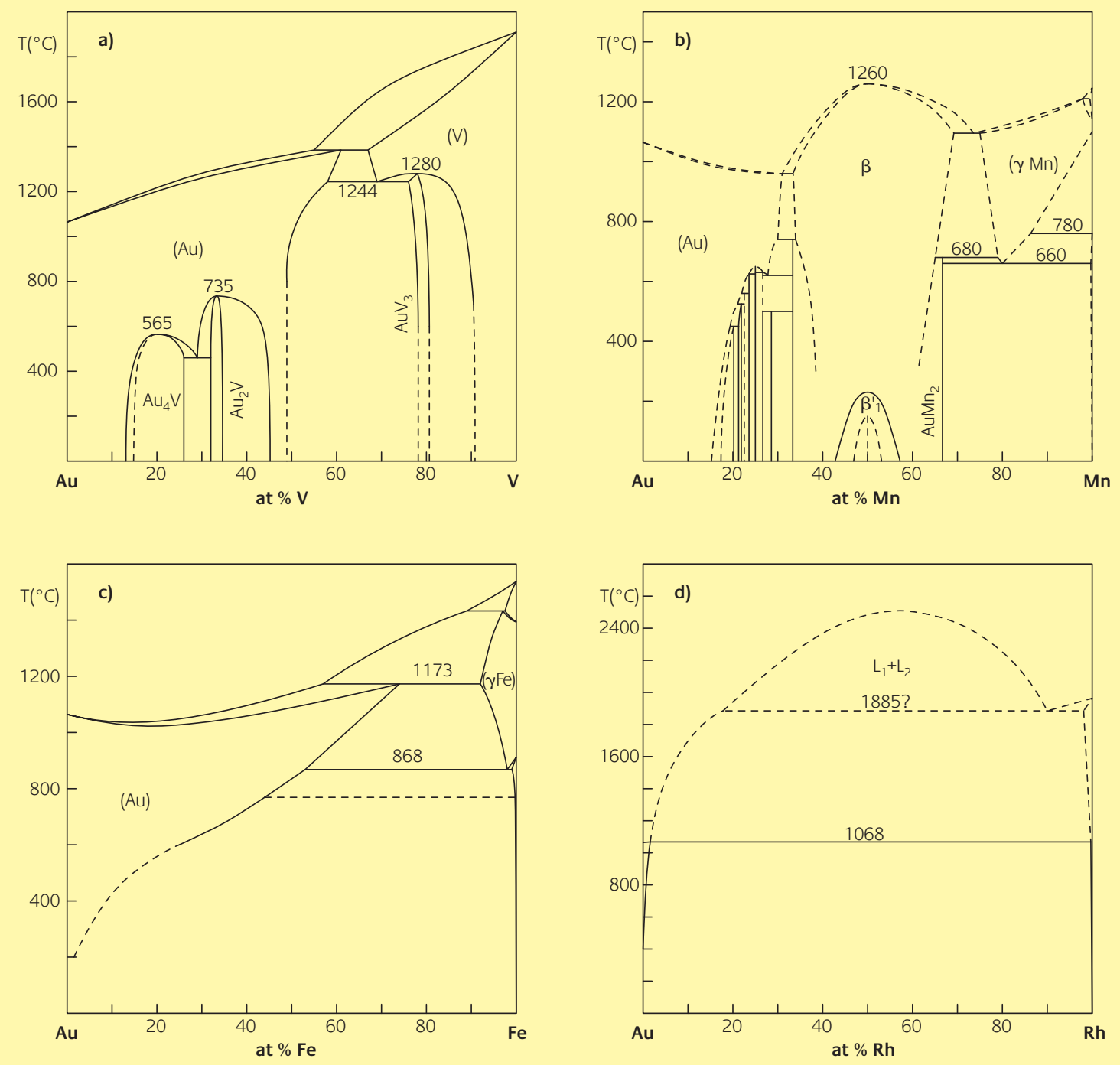

\section{Figure 4}

Phase diagrams of typical gold binary systems with elements from 5th to 9th group of the Periodic Table. a) Au-V phase diagram; b) Au-Mn phase diagram c) Au-Fe phase diagram; d) Au-Rh phase diagram

In comparison with the previous set of diagrams, they show more intermetallic bonding, and generally a decrease in the number of stoichiometric compounds and in the stability of the intermediate phases. See in Fig. 3 the values computed according to Miedema and in Table 1 the maximum values observed in each system of the so-called Raynor's index (23), which gives an indication of the thermal stability of the intermediate phases. This index is the normalized melting temperature defined in the case of an $A_{1-x} B_{x}$ compound, as:

$$
I_{s}=T_{m}\left(A_{1-x} B_{x}\right) /\left[(1-x) T_{m}(A)+x T_{m}(B)\right]
$$

where $T_{m}$ is the melting (or transformation) temperature expressed in Kelvin degrees. Values of $I_{s}$ higher than 1 indicate high stabilities.
In this set of diagrams the formation of solid solutions can be highlighted. Fig. 5 gives a sketch of the composition ranges of the solid solutions in gold of the transition elements for which reliable data are available. A complex trend can be noticed as a function of the position of the partner element in the Periodic Table. It is known (see, for instance, Massalski (24)) that this trend can be related to the interplay of the different factors determining solid solubilities. An approach to this point may be given by the Hume-Rothery rules for primary solid solutions. A summary of these rules is in the following:

a) solid solubility should become restricted if the difference between the atomic sizes of the component elements forming an alloy exceeds about 14-15\% (15\% rule).

b) primary solid solubility will be restricted by the formation 


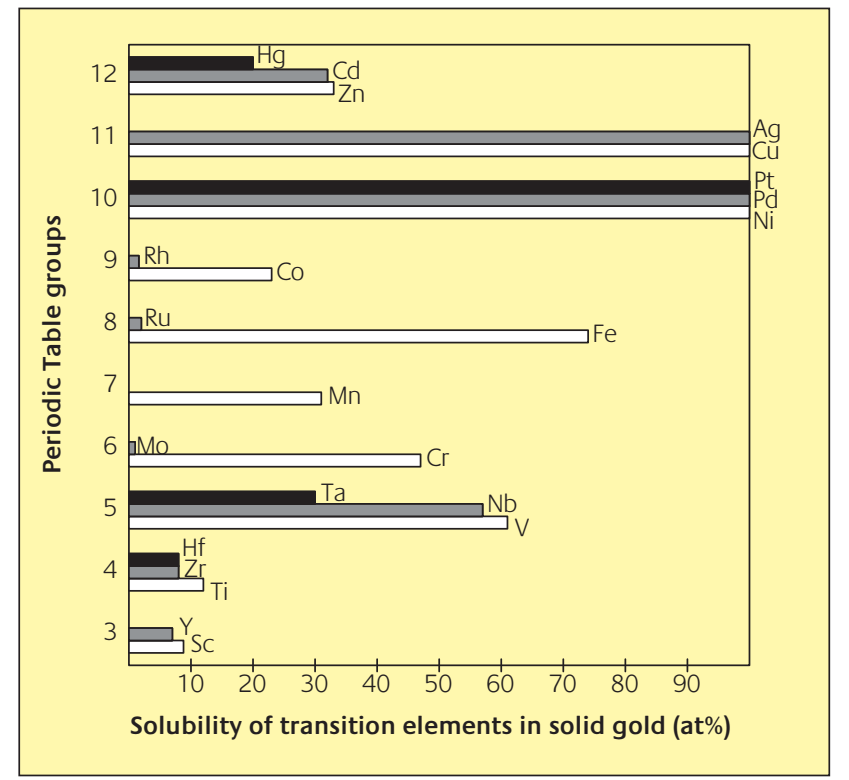

\section{Figure 5}

Solid solubilities of the transition elements in gold. Notice that for Cu, Ag, Ni, Pd, Pt the formation of continuous solid solutions may be observed generally at high temperature

of stable intermediate compounds (electrochemical effect).

c) the extent of the solid solubility and the stability of certain intermediate phases strongly depend on the electron concentration (V.E.C., average number of Valence Electron per atom). The contribution of 3 Valence electrons per atom is considered for $\mathrm{Al}, 4$ for $\mathrm{Ge}, \mathrm{Sn}$, etc. For the metals of the 11th and 12th groups, in a simple evaluation of these data, the electrons only belonging to the $n$ s shell are considered: 1 for $\mathrm{Cu}, \mathrm{Ag}, \mathrm{Au}, 2$ for $\mathrm{Zn}, \mathrm{Cd}$, $\mathrm{Hg}$.

Within this group of alloys the Au-Mn system may be worthy of a special mention. Its phase diagram, reported in Fig. 4b, is characterized by the formation of a number of compounds such as $\mathrm{Au}_{31} \mathrm{Mn}_{9}, \mathrm{Au}_{72} \mathrm{Mn}_{21}, \mathrm{Au}_{41} \mathrm{Mn}_{12}, \mathrm{Au}_{167} \mathrm{Mn}_{49}$, $\mathrm{Au}_{95} \mathrm{Mn}_{28}, \mathrm{Au}_{27} \mathrm{Mn}_{8}$, close to each other in a small range of composition (22.50 to 22.86 at\% Mn) $(25,26)$. A similar behaviour is shown by the Au-Mg system, in which several phases in the composition range around the $\mathrm{MgAu}_{3}$ composition were reported: $\mathrm{Mg}_{26} \mathrm{Au}_{74}, \mathrm{Mg}_{24} \mathrm{Au}_{76}$, etc. (27). All these are "superstructures" of close-packed structures characterised by long period stacking sequences of similar "substructures".

\section{-Au alloys with the elements of the 10th to 12th groups}

The very important Au-Ni, Au-Cu and Au-Zn binaries belong to this set of systems. The Au-Cu and Au-Ni phase diagrams are shown in Fig. 6. In all these systems large fields of solid solutions are found. At high temperatures a single solid

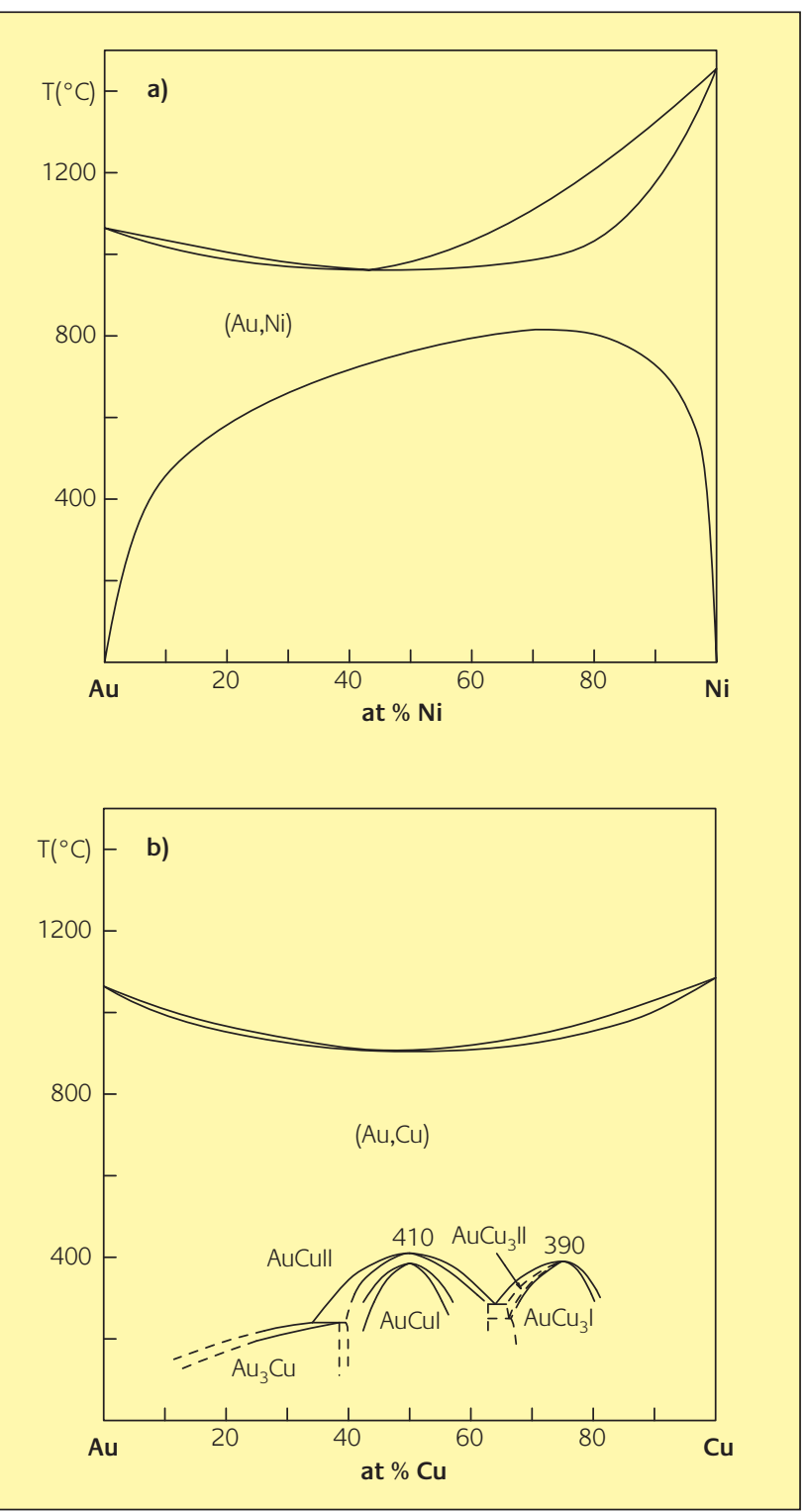

\section{Figure 6}

Phase diagrams of the Au-Ni and Au-Cu systems. Notice the solid solutions stable in the complete range of composition at high temperature. In the Ni-alloys a nearly complete demixing on cooling is present. In the Cu-alloys at low temperature the formation of several ordered structures can be highlighted

solution phase occurs in the Au-Ni, Au-Cu, Au-Pd, Au-Pt and Au-Ag. At lower temperatures in the Au-Ni and Au-Pt systems, a miscibility gap appears as a result of the solid state decomposition of the high temperature single phase into two terminal solid solution phases.

More complex behaviour is shown by Au-Cu and Au-Pt alloys. The typical behaviour of Au-Cu alloys has been studied and described in full detail. For instance, in the assessment of the system by Okamoto et al. (28), the results obtained in several investigations have been summarized. The phase diagram (see Fig. 6 and also Fig. 5) shows in the solid state, 


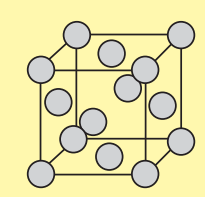

(a)

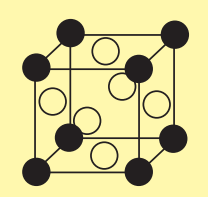

(b)

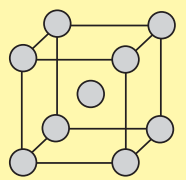

(d)

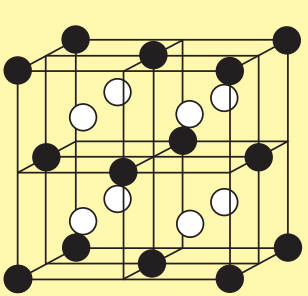

(f)

(e)

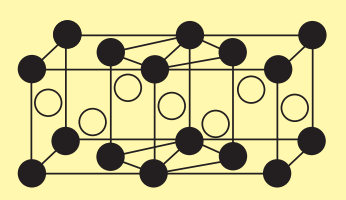

(c)

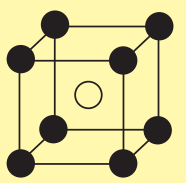

\section{Figure 7}

Simple typical alloy structures (and their variants).

a), b), c): $\mathrm{Cu}$ and its derivative structures (AuCu 3 and $\mathrm{AuCu}$ (II) types).

d), e): W-type and CsCl-type structures

f): $\mathrm{CaF}_{2}$-type structure

at high temperature, a solid substitutional solution in the complete composition range from $\mathrm{Au}$ to $\mathrm{Cu}$. The crystal structure of the two elements is the same and corresponds to the simple, close packed, face-centered cubic unit cell (depicted in Fig. 7a). The same structure is maintained, for all compositions, in the disordered high temperature solid solution, where the two atoms may randomly substitute each other in all the positions. These positions are still equivalent to each other, each of them being statistically occupied in a given ratio (equal to the overall alloy composition) by Cu or (and) Au. As may be seen in Fig. 6, by lowering the temperature, the alloys undergo transformations corresponding to ordering processes, as a consequence of which the different positions in the unit cell are preferentially occupied by $\mathrm{Cu}$ or $\mathrm{Au}$. The ordered structures which may be obtained for atomic ratios 1:3 or 1:1 are shown in Fig. 7b and 7c.

As for the Au-Zn system, its phase diagram may be considered typically representative of the so-called HumeRothery alloys. In a number of such systems, there are, indeed, similar crystal structures the formation of which may be related to the Valence electron concentration.

In Fig. 8 a comparison is made between a few of these systems. The Cu-Zn, Ag-Zn and Au-Zn show a number of similar features. For instance, at 50 at\% composition, the so-
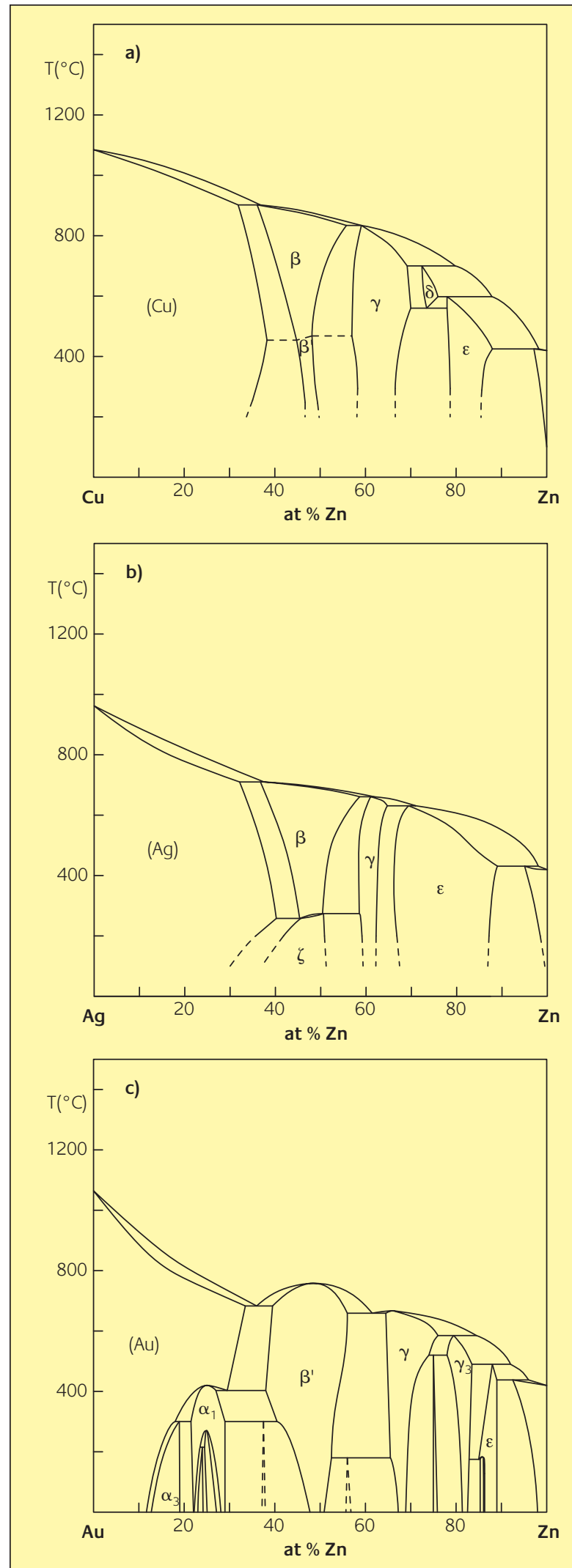

\section{Figure 8}

Typical representative phase diagrams of Hume-Rothery alloys. a) Cu-Zn phase diagram; b) Ag-Zn phase diagram; c) Au-Zn phase diagram 
called $\beta$ phase is formed having the structure depicted in Fig. $7 d$ and characterised by 3 Valence electrons for 2 atoms (VEC $=1.5)$. For higher Zn-content (higher VEC) several other phases are formed (see also Table 2). An interesting well-known consequence is presented in Fig. 9 where the Cu-Zn diagram is reported together with those of $\mathrm{Cu}$ with the electron richer elements, $\mathrm{Al}$ and $\mathrm{Sn}$. In terms of atomic composition, smaller quantities of $\mathrm{Al}$ and $\mathrm{Sn}$ are sufficient to produce the same structures given by a certain quantity of $\mathrm{Zn}$. This is even more evident in the drawing reported in many textbooks and shown in Fig. 10 where the stability fields of a few phases are reported directly in terms of VEC.

Several silver and gold alloys show a behaviour coherent with these general rules (see also the phases listed in Table 2), even if mainly in the case of gold, possibly due to its higher electronegativity value, more complex reactivity is observed. See, for instance, the Au-Al phase diagram in Fig. 11a, where the fields of the highly stable, nearly stoichiometric, compounds in the Al-rich region distort the gold-rich region.

The structure of the simple body-centered structure (shown at $298 \mathrm{~K}$ by different elements such as $\mathrm{Na}, \mathrm{K}, \mathrm{Rb}, \mathrm{Ba}$, $\mathrm{V}, \mathrm{Nb}, \mathrm{Cr}, \mathrm{Mo}, \mathrm{W}$, etc.) is presented in Fig. $7 \mathrm{~d}$. The same structure is observed in a number of binary alloys such as the $\beta$-Cu-Zn phase in a composition range 36.1 to 59.1 at\% Zn (compare with Fig. 9). In this case the two positions in the cubic cell, at the origin (at the vertices of the cube) and in the centre are statistically equivalent because they have the same probability of occupancy by Cu and Zn. In Fig. 7e the derived ordered structure of the $\beta^{\prime}$ phase is shown. In this case, the two positions are no longer equivalent and,

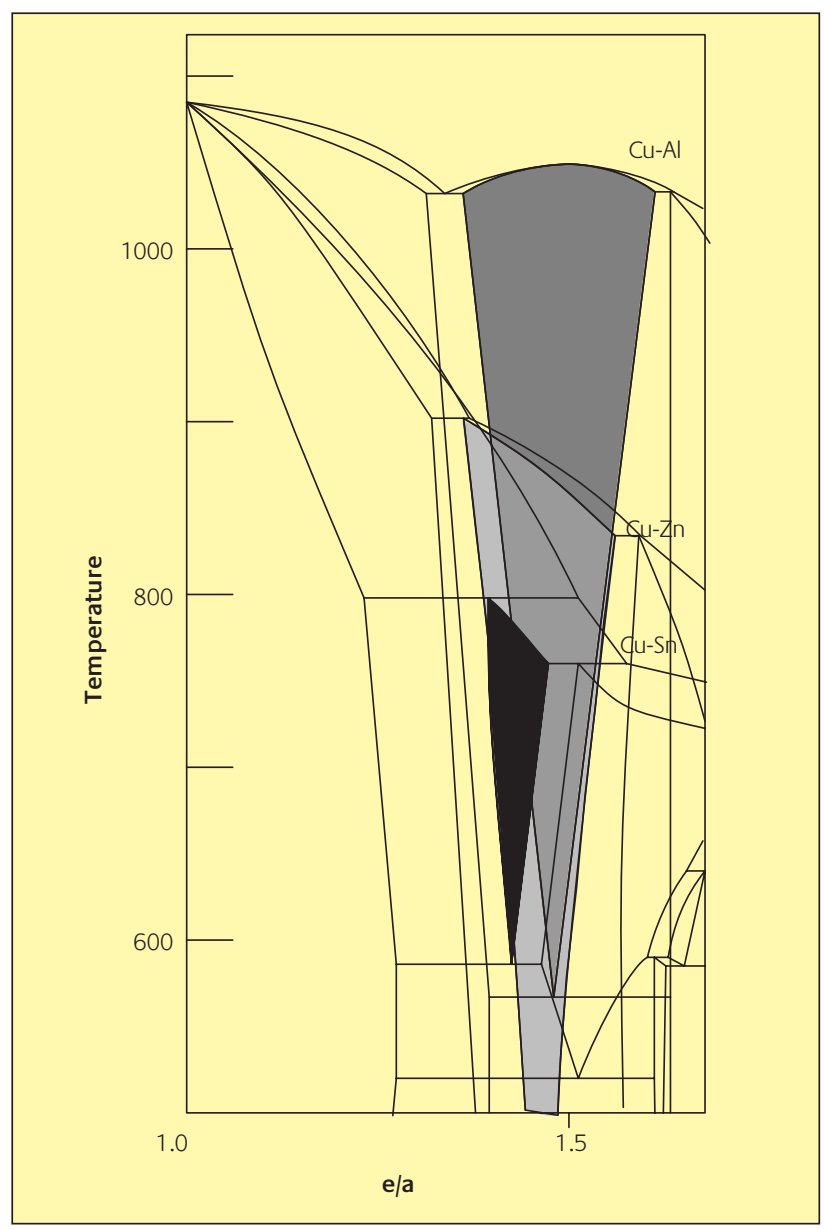

\section{Figure 10}

The Cu-rich regions of the Cu-Zn, Cu-Al and Cu-Sn phase diagrams drawn with the same e/a (ratio between Valence electron numbers and atom numbers, also called VEC) scale are superimposed. Notice that the three $\beta$ phases (dotted regions) are formed around the same e/a value

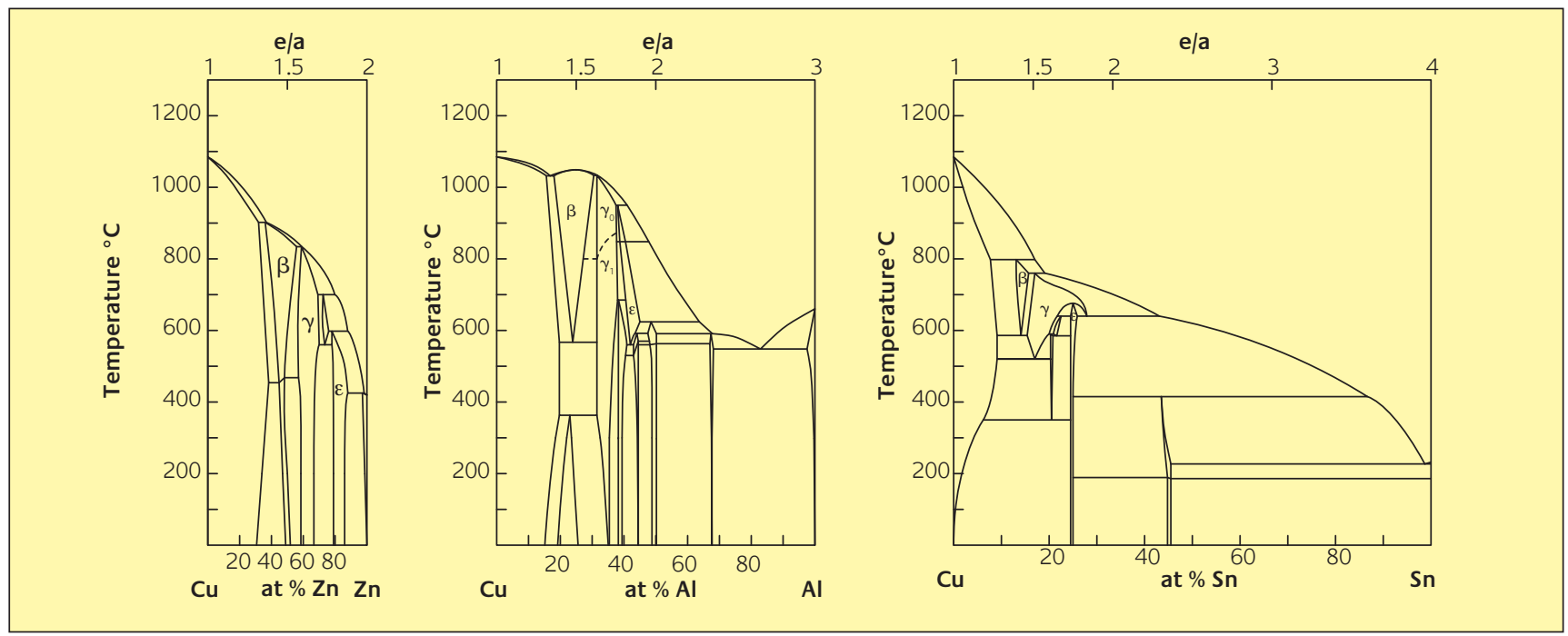

Figure 9

Cu-Zn, Cu-Al and Cu-Sn phase diagrams. The three diagrams have been drawn with different length of the $x$-axis in order to have the same scale for the e/a values 
Table 2

Examples of "Hume-Rothery" phases given by the coinage metals

\begin{tabular}{|c|c|c|c|c|c|}
\hline & \multicolumn{3}{|c|}{ Electron atom ratio $3: 2$} & \multirow{2}{*}{$\begin{array}{c}\text { Electron atom } \\
\text { ratio } 21: 13 \\
\gamma \text { brass structure } \\
(\gamma)\end{array}$} & \multirow{2}{*}{$\begin{array}{c}\text { Electron atom } \\
\text { ratio } 7: 4 \\
\text { Close packed } \\
\text { hexagonal } \\
\text { structure }(\varepsilon)\end{array}$} \\
\hline & $\begin{array}{l}\text { Body-centered } \\
\text { cubic }(\beta)\end{array}$ & $\begin{array}{l}\text { Complex cubic } \\
\beta \text { manganese } \\
\text { structure }\end{array}$ & $\begin{array}{l}\text { Close-packed } \\
\text { hexagonal } \\
\text { structure }\end{array}$ & & \\
\hline & AuMg & $\mathrm{Au}_{3} \mathrm{Al}$ & $\mathrm{Au}_{3} \mid \mathrm{n}$ & $\mathrm{Au}_{5} \mathrm{Zn}_{8}$ & $\mathrm{AuZn}_{3}$ \\
\hline \multirow[t]{5}{*}{ Au-alloys } & AuCd & & $\mathrm{Au}_{5} \mathrm{Sn}$ & $\mathrm{Au}_{5} \mathrm{Cd}_{8}$ & $\mathrm{AuCd}_{3}$ \\
\hline & & & & $\mathrm{Au}_{9} \mid \mathrm{n}_{4}$ & $\mathrm{Au}_{3} \mathrm{Sn}$ \\
\hline & & & & & $\mathrm{Au}_{5} \mathrm{Al}_{3}$ \\
\hline & $\mathrm{AgMg}$ & $\mathrm{Ag}_{3} \mathrm{Al}$ & AgZn & $\mathrm{Ag}_{5} \mathrm{Zn}_{8}$ & $\mathrm{AgZn}_{3}$ \\
\hline & AgZn & & $\mathrm{AgCd}$ & $\mathrm{Ag}_{5} \mathrm{Cd}_{8}$ & $\mathrm{AgCd}_{3}$ \\
\hline \multirow[t]{7}{*}{ Ag-alloys } & $\mathrm{AgCd}$ & & $\mathrm{Ag}_{3} \mathrm{Al}$ & $\mathrm{Ag}_{5} \mathrm{Hg}_{8}$ & $\mathrm{Ag}_{3} \mathrm{Sn}$ \\
\hline & $\mathrm{Ag}_{3} \mathrm{ln}$ & & $\mathrm{Ag}_{3} \mathrm{Ga}$ & $\mathrm{Agg}_{9} \mathrm{In}_{4}$ & $\mathrm{Ag}_{5} \mathrm{Al}_{3}$ \\
\hline & & & $\mathrm{Ag}_{5} \mathrm{Sn}$ & & \\
\hline & & & $\mathrm{Ag}_{7} \mathrm{Sb}$ & & \\
\hline & CuBe & $\mathrm{Cu}_{5} \mathrm{Si}$ & $\mathrm{Cu}_{3} \mathrm{Ga}$ & $\mathrm{Cu}_{5} \mathrm{Zn}_{8}$ & $\mathrm{CuZn}_{3}$ \\
\hline & CuZn & & $\mathrm{Cu}_{5} \mathrm{Ge}$ & $\mathrm{Cu}_{5} \mathrm{Cd}_{8}$ & $\mathrm{CuCd}_{3}$ \\
\hline & $\mathrm{Cu}_{3} \mathrm{Al}$ & & & $\mathrm{Cu}_{5} \mathrm{Hg}_{8}$ & $\mathrm{Cu}_{3} \mathrm{Sn}$ \\
\hline \multirow[t]{5}{*}{ Cu-alloys } & $\mathrm{Cu}_{3} \mathrm{Ga}$ & & & $\mathrm{Cu}_{9} \mathrm{Al}_{4}$ & $\mathrm{Cu}_{3} \mathrm{Ge}$ \\
\hline & $\mathrm{Cu}_{3} \mathrm{ln}$ & & & $\mathrm{Cu}_{9} \mathrm{Ga}_{4}$ & $\mathrm{Cu}_{3} \mathrm{Si}$ \\
\hline & $\mathrm{Cu}_{5} \mathrm{Si}$ & & & $\mathrm{Cugln}_{4}$ & \\
\hline & $\mathrm{Cu}_{5} \mathrm{Sn}$ & & & $\mathrm{CU}_{31} \mathrm{Si}_{8}$ & \\
\hline & & & & $\mathrm{Cu}_{31} \mathrm{Sn}_{8}$ & \\
\hline
\end{tabular}

for an equiatomic composition, the $\mathrm{Cu}$ atoms occupy one position, the $\mathrm{Zn}$ atoms the other. The same structure is presented by a number of intermetallic compounds (see the examples reported in Table 2) and also by several ionic compounds $(\mathrm{CsCl}$ is considered the prototype of this structure).

\section{-Au alloys with the elements of the 13th to 16th groups}

The trend for gold alloying behaviour in this region of the Periodic Table corresponds to a decrease in the number of compounds.

The Au-Al diagram (see Fig. 11a) shows the formation of the high melting $\mathrm{AuAl}_{2}$ phase. The characteristics of this phase have been recently summarised by Cahn (29). This phase, indeed, is an example of coloured intermetallic phase. The formation of this phase is also observed when gold wires are bonded to aluminium surfaces or aluminium wires to gold surfaces, leading to mechanical failure, either because of the intrinsic brittleness of the phase or because of voids formed during rapid interdiffusion of the two metals. The first integrated circuits suffered from this phenomenon, known as purple plague. The crystal structure of $\mathrm{Al}_{2} \mathrm{Au}$ was determined as simple cubic $\mathrm{CaF}_{2}$-type (see Fig. 7f), but more recently, it was found that the Al sublattice is incompletely occupied, in which case the composition is close to $\mathrm{Au}_{6} \mathrm{Al}_{11}$. The melting point of this phase is a hundred degrees above that of aluminium, giving an indication of its high thermodynamic stability. The intense purple colour of $\mathrm{Al}_{2} \mathrm{Au}$ and the fact that it seems (as $\mathrm{PtAl}_{2}$ ) to be much easier to synthesize than other artificial precious stones, could be of growing interest for jewellery incorporating intermetallic compounds.

With the light non-metallic elements B, C, N, O, Si, P, S no gold stable compounds have been described. However, a number of metastable phases are known, for instance, the instable explosive $\mathrm{AuN}_{3}$ and the metastable $\mathrm{Au}_{3} \mathrm{~N}_{2}$ which can be synthesised by wet chemistry reactions. The diagrams of Au with $\mathrm{Si}, \mathrm{Ge}$, As are of the simple eutectic type ( $P$ and $S$ also give eutectic equilibria interfering, however, with a boiling equilibrium). A similar diagram is shown by Se with Au, under a constant pressure. In this case the diagram presented in Fig. 11d, was obtained by studying the mixtures in sealed ampoules (and therefore at a variable pressure). 

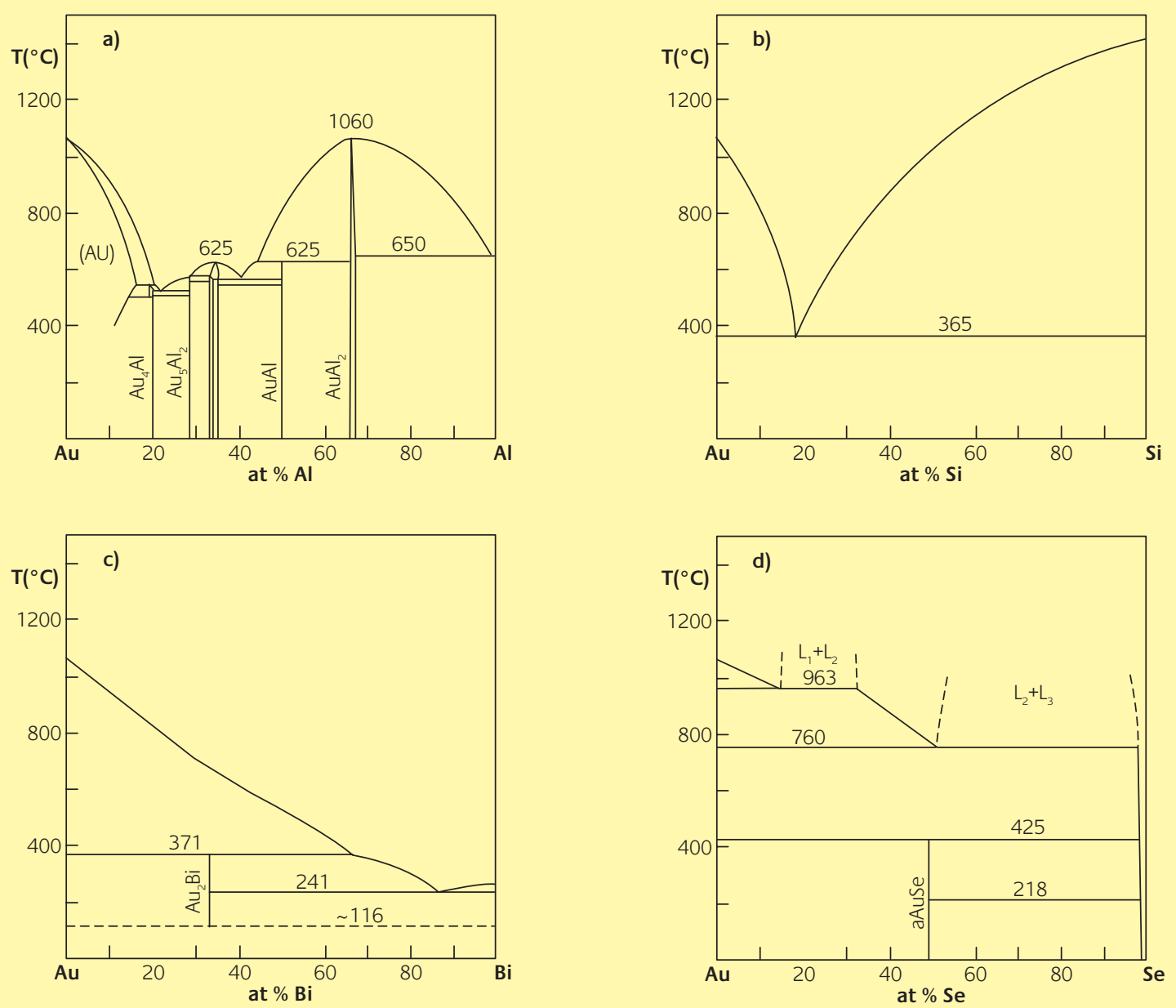

\section{Figure 11}

Phase diagrams of typical gold binary systems with elements of the 13th to 16th group of the Periodic Table. a) Au-Al phase diagram; b) Au-Si phase diagram; c) Au-Bi phase diagram; d) Au-Se phase diagram

\section{Gold binary intermetallic phases}

In the previous description of the gold binary alloys we have noticed the formation in several systems of intermediate phases (both stoichiometric and those with solid solution ranges). A summary of the formation of these phases is shown in Fig. 12. As seen before in the diagrams previously reported, intermediate phases present in the systems pertain to various types and form through different mechanisms (either by crystallization from the melt or by ordering in the solid state). On the whole, we see two sets of elements giving intermediate phases. The first set is on the left of the Periodic Table and corresponds to the formation of stoichiometric compounds with high melting and strongly negative $\Delta \mathrm{H}$ of formation (compare with Fig. 3). Moving towards the right side of the Periodic Table we have the second set of alloys (for instance $\mathrm{Cd}$, $\mathrm{Ga}$, In, etc.) generally showing low melting points, large solid solubility fields and lower $\Delta \mathrm{H}$ of formation.
A number of these phases are formed through solid-state reactions. Finally, at the far right of the Periodic Table compounds with semi-metals and non-metals are formed.

A few comments about compositions and structures of these phases may be noteworthy.

As for the stoichiometry, the M-Au compounds (either stoichiometric or intermediate solid solutions) range from 10 at\% (as in $\mathrm{Sr}_{9} \mathrm{Au}$ ) up to 91 at\% Au (as in the Au-richest phase of the Au-Sn system).

The most common stoichiometries are collected in Table 3, together with their structural types. As usual in crystallochemistry each structural type is identified by its prototype (the first compound found with such a structure) and the Pearson symbol, which gives the crystal system, the lattice type and number of atoms in the unit cell (for instance: CF24-MgCu 2 means that the cubic, Face-centred cell contains 24 atoms (in the specific case $8 \mathrm{Mg}$ and $16 \mathrm{Cu}$ and, in general case of an $\mathrm{AX}_{2}$ compound with such a 


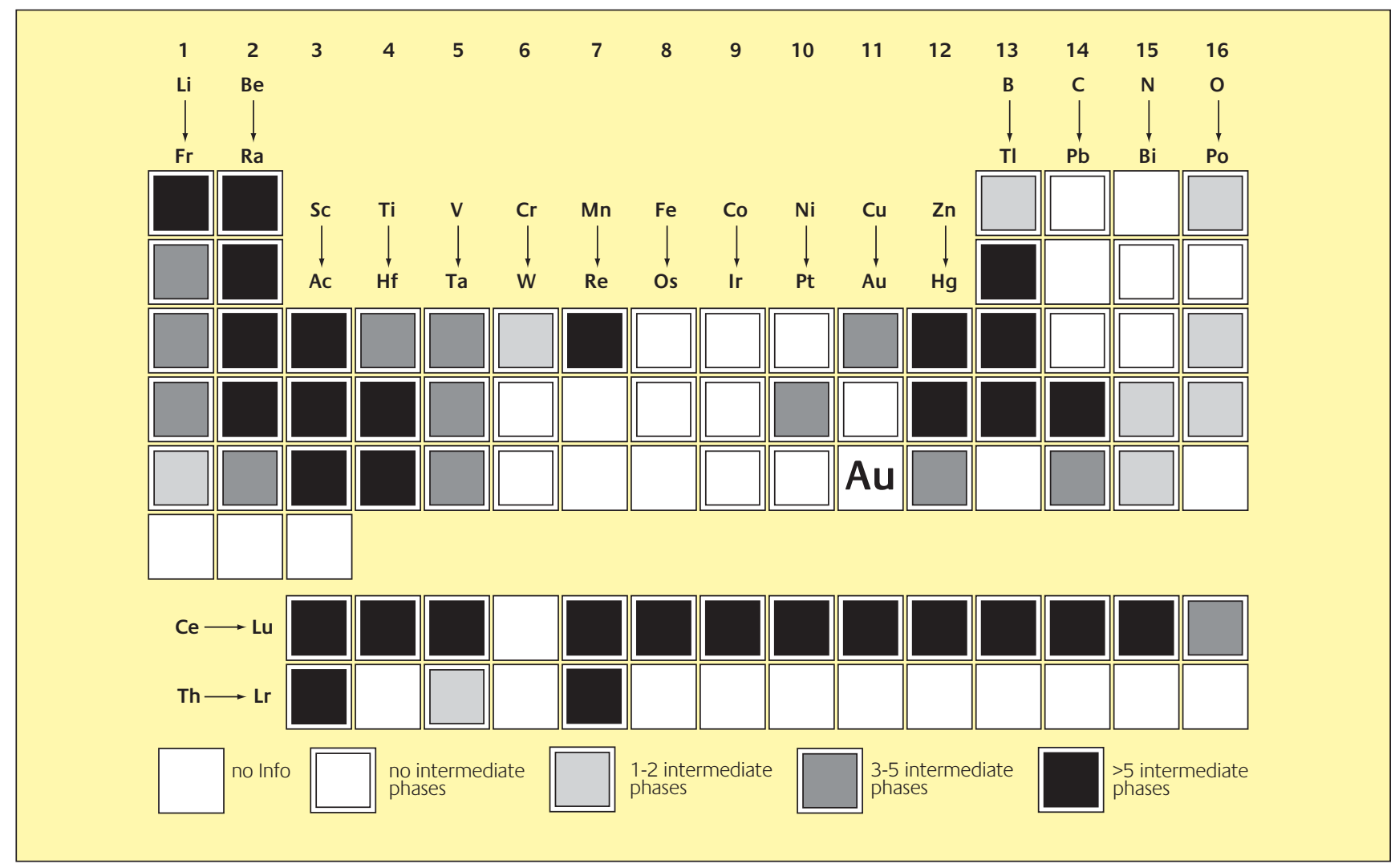

\section{Figure 12}

Compound formation capability. For the different elements (up to the 16th group) ordered as in the Periodic Table an approximate indication is given of the number of intermediate phases formed in the binary Au-alloys. (see text)

structure, 8 atoms $\mathrm{A}$ and $16 \mathrm{X}$ in the same positions as $\mathrm{Mg}$ and $\mathrm{Cu}$ in the prototype).

The representation of a few common, typical structures of intermetallic compounds, found also in gold alloys is shown, with some comments, in Fig. 7.

An analysis of the structural characteristics (and of their trend) of the reported phases shows that generally high coordination numbers for all the atoms are present, typically values such as 12-14. (the coordination number, $\mathrm{CN}$, is the number of neighbouring atoms around a given atom). The coordination around the partner atoms, especially if these have a large radius and the gold concentration is high, may be much higher (for instance, 18 Au atoms close (around) to one $\mathrm{Ba}$ (or $\mathrm{Cs}$, Eu, etc.) atom in the $\mathrm{CaCu}_{5}$ type structure).

The behaviour shown by compounds having less metallic bonding is of course different. For instance, in the more covalent $\mathrm{AuSb}_{2}$ compound, the coordination around $\mathrm{Au}$ is 6 and around $\mathrm{Sb}$ is 4; similarly in AuTe 2 the two coordination numbers are 6.

Moreover, with special reference to the authors' scientific work (for instance, see refs. (13, 14, 15, 16, 18, 19), a particular group of Au intermetallics is presented in Fig. 13. These are compounds with the rare earth metals (R). It is known that the alloys of these elements, particularly those of the trivalent lanthanides (that is with the exception of the divalent $\mathrm{Eu}$ and $\mathrm{Yb}$ ) show, as a function of the $\mathrm{R}$ atomic number, a gradual change in their properties. In the specific case of the equiatomic compounds RAu we see in Fig. 13a the gradual increase in the negative value of the enthalpy of formation. This increase in stability may be related to the increase in melting point (highlighted also by the trend of the so-called reduced melting temperature, defined by the ratio between the melting temperatures, in Kelvin degrees, of the R-compound and of the rare earth involved). Another correlation could be done with the volume contraction in the synthesis of the alloys. In this case a volume contraction in the order of $5-8 \%$ can be observed (higher volume contractions may be observed in the gold alloys of the alkaline earth metals ( $\Delta V \approx 16 \%$ ) and alkali metals (up to $\Delta V \approx 40 \%)$ ).

Notice, finally, that the properties considered in this "family" of intermetallic phases (and their trends) may conveniently be used in discussing also the behaviour shown by other groups of alloys, for instance, the actinides alloys, those formed by the alkali metals, etc. 


\section{Table 3}

More common stoichiometries of binary gold intermetallics. A selection of gold phases, their structural types and coordination numbers are listed (according to (7)). Notice that some structural types ( $\mathrm{Pu}_{3} \mathrm{Pd}_{4}$ and $\mathrm{Gd} \mathrm{d}_{7} \mathrm{Au} \mathrm{u}_{10}$ for instance) have many representatives belonging to alloys of the rare earth family $(R)$

\begin{tabular}{|c|c|c|c|c|}
\hline Stoichiometry & Phases & Structural type & $\begin{array}{l}\text { Coordination } \\
\text { around } \mathrm{Me}\end{array}$ & $\begin{array}{l}\text { Coordination } \\
\text { around } \mathrm{Au}\end{array}$ \\
\hline \multirow[t]{6}{*}{$\mathrm{M}_{3} \mathrm{Au}$} & $\mathrm{Nb}_{3} \mathrm{Au}, \mathrm{Ta}_{4} \mathrm{Au}, \mathrm{Ti}_{3} \mathrm{Au}, \mathrm{V}_{3} \mathrm{Au}$ & $\mathrm{cP} 8-\mathrm{Cr}_{3} \mathrm{Si}$ & 12 & 12 \\
\hline & $\mathrm{Eu}_{3} \mathrm{Au}$ & oP16- $\mathrm{Fe}_{3} \mathrm{C}$ & $14-15$ & 11 \\
\hline & $\mathrm{AuLi}_{3}$ & $\mathrm{cF} 16-\mathrm{BiF}_{3}$ & 14 & 14 \\
\hline & $\mathrm{Mg}_{3} \mathrm{Au}$ & hP8-Na ${ }_{3} \mathrm{As}$ & $9-11$ & 11 \\
\hline & $\mathrm{Cu}_{3} \mathrm{Au}(\mathrm{I}), \mathrm{Pd}_{3} \mathrm{Au}$ & $\mathrm{cP} 4-\mathrm{AuCu}_{3}$ & 14 & 12 \\
\hline & $\mathrm{Pb}_{3} \mathrm{Au}$ & $\mathrm{t} \mid 32-\alpha V_{3} S$ & $14-15$ & 8 \\
\hline \multirow[t]{6}{*}{$\mathrm{M}_{2} \mathrm{Au}$} & $\begin{array}{l}\mathrm{R}_{2} \mathrm{Au}(\mathrm{R}=\mathrm{Ce}, \mathrm{Dy}, \mathrm{Er}, \mathrm{Gd}, \mathrm{Ho}, \mathrm{La}, \mathrm{Lu}, \\
\mathrm{Nd}, \mathrm{Pr}, \mathrm{Sm}, \mathrm{Tb}, \mathrm{Tm}, \mathrm{Sc}, \mathrm{Y})\end{array}$ & $\mathrm{oP} 12-\mathrm{CO}_{2} \mathrm{Si}$ & 13 & 10 \\
\hline & $\mathrm{Na}_{2} \mathrm{Au}, \mathrm{Pb}_{2} \mathrm{Au}, \mathrm{Th}_{2} \mathrm{Au}$ & $\mathrm{t} \mid 12-\mathrm{Al}_{2} \mathrm{Cu}$ & 15 & 10 \\
\hline & $\mathrm{Al}_{2} \mathrm{Au}, \mathrm{Ga}_{2} \mathrm{Au}, \mathrm{In}_{2} \mathrm{Au}$ & $\mathrm{CF}_{12}-\mathrm{CaF}_{2}$ & 10 & 8 \\
\hline & $\mathrm{Hf}_{2} \mathrm{Au}, \mathrm{Mn}_{2} \mathrm{Au}$ & tI6-MoSi & 14 & 14 \\
\hline & $\mathrm{Sb}_{2} \mathrm{Au}$ & $\mathrm{cP} 12-\mathrm{FeS}_{2}$ & 4 & 6 \\
\hline & $\mathrm{Te}_{2} \mathrm{Au}$ & $\mathrm{mC6}-\mathrm{AuTe}_{2}$ & 6 & 6 \\
\hline \multirow[t]{7}{*}{ MAu } & $\begin{array}{l}\text { AuCd, CsAu, LiAu( }\left(\beta^{\prime}\right), \operatorname{RAu}(\mathrm{R}=\mathrm{Dy}, \mathrm{Er} \\
\mathrm{Gd}, \mathrm{Ho}, \mathrm{Lu}, \mathrm{Nd}, \mathrm{Pr}, \mathrm{Sm}, \mathrm{Tb}, \mathrm{Tm}), \mathrm{MgAu} \\
\mathrm{Au}-\mathrm{Mn}(\beta), \mathrm{RbAu}, \mathrm{ScAu}, \mathrm{AuTi}(\gamma), \mathrm{YAu}\end{array}$ & cP2-CsCl & 14 & 14 \\
\hline & $\begin{array}{l}\text { RAu (R=Ce, Dy, Er, Gd, Ho, La, Nd, Pr, Sm, } \\
\text { Tb, Tm), ThAu }\end{array}$ & oC8-CrB & 17 & 9 \\
\hline & RAu (R=Ce, Eu, La, Nd, Pr) & oP8-FeB & 17 & 9 \\
\hline & $\mathrm{AuCu}(\mathrm{I})$ & tP4-AuCu & 12 & 12 \\
\hline & GaAu & oP8-MnP & & \\
\hline & $\alpha H f A u, \alpha A u T i$ & tP4- $\gamma$ CuTi & 14 & 14 \\
\hline & $\beta A u T i$ & oP4-AuCd & 12 & 12 \\
\hline $\mathrm{M}_{3} \mathrm{Au}_{4}$ & $\mathrm{R}_{3} \mathrm{Au}_{4}(\mathrm{R}=\mathrm{Ce}, \mathrm{Gd}, \mathrm{La}, \mathrm{Nd}, \mathrm{Pr}, \mathrm{Sm}, \mathrm{Tb}), \mathrm{Th}_{3} \mathrm{Au} \mathrm{u}_{4}$ & $\mathrm{hR} 42-\mathrm{Pu}_{3} \mathrm{Pd}_{4}$ & 16 & $12-14$ \\
\hline $\mathrm{M}_{7} \mathrm{Au}_{10}$ & $\mathrm{R}_{7} \mathrm{Au}_{10}(\mathrm{R}=\mathrm{Dy}, \mathrm{Er}, \mathrm{Gd}, \mathrm{Ho}, \mathrm{Sm}, \mathrm{Tb}, \mathrm{Tm})$ & $\mathrm{t} / 136-\mathrm{Gd}_{7} \mathrm{Au}_{10}$ & $12-17$ & $10-11$ \\
\hline \multirow[t]{5}{*}{$\mathrm{MAu}_{2}$} & $\begin{array}{l}\gamma \mathrm{AlAu}_{2}, \mathrm{BeAu}_{2}, \mathrm{RAu}_{2}(\mathrm{R}=\mathrm{Dy}, \mathrm{Er}, \mathrm{Gd}, \mathrm{Ho}, \mathrm{Lu} \\
\mathrm{Tm}, \mathrm{Tb}), \mathrm{HfAu} u_{2}, \mathrm{MnAu}_{2}, \mathrm{ScAu}_{2}, \mathrm{TiAu}_{2}\end{array}$ & tl6-MoSi & 14 & 14 \\
\hline & $\mathrm{RAu}_{2}(\mathrm{R}=\mathrm{Ce}, \mathrm{Eu}, \mathrm{La}), \mathrm{SrAu} 2$ & ol12- $\mathrm{CeCu}_{2}$ & 16 & 10 \\
\hline & $\mathrm{BiAu}_{2}, \mathrm{NaAu}_{2}, \mathrm{PbAu}_{2}$ & $\mathrm{cF} 24-\mathrm{Cu}_{2} \mathrm{Mg}$ & 16 & 12 \\
\hline & $\mathrm{BaAu}_{2}, \mathrm{NbAu}_{2}, \mathrm{ThAu}_{2}$ & $\mathrm{hP} 3-\mathrm{AlB}_{2}$ & 20 & 9 \\
\hline & $\mathrm{UAu}_{2}$ & hP3-CeCd 2 & 14 & 14 \\
\hline \multirow[t]{2}{*}{$\mathrm{MAu}_{3}$} & $\begin{array}{l}\mathrm{RAu}_{3}(\mathrm{R}=\mathrm{Dy}, \mathrm{Er}, \mathrm{Gd}, \mathrm{Ho}, \mathrm{Lu}, \mathrm{Sm}, \mathrm{Tb}, \mathrm{Tm}) \\
\mathrm{HfAu}_{3}, \mathrm{Au}-\operatorname{In}\left(\varepsilon^{\prime}\right), \mathrm{ScAu} u_{3}\end{array}$ & oP8-TiCu 3 & 12 & 12 \\
\hline & $\mathrm{CdAu}_{3}(\alpha 1), \mathrm{CuAu}_{3}, \mathrm{Li}-\mathrm{Au}(\alpha 1), \mathrm{PdAu}_{3}$ & $\mathrm{CP} 4-\mathrm{AuCu}_{3}$ & 12 & 12 \\
\hline $\mathrm{M}_{14} \mathrm{Au}_{51}$ & 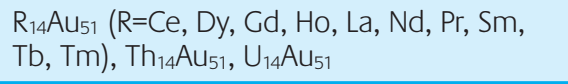 & hP65-Gd ${ }_{14} \mathrm{Ag}_{51}$ & & \\
\hline \multirow[t]{2}{*}{$\mathrm{MAu}_{4}$} & $\begin{array}{l}\alpha^{\prime} \mathrm{Au}-\mathrm{Cr}, \mathrm{RAu}_{4}(\mathrm{R}=\mathrm{Er}, \mathrm{Ho}, \mathrm{Lu}), \mathrm{MnAu}_{4}, \\
\mathrm{ScAu}_{4}, \mathrm{TiAu}_{4}, \mathrm{VAu}_{4}\end{array}$ & tl10-MoNi 4 & 12 & 12 \\
\hline & $\mathrm{HfAu}_{4}$ & $\mathrm{oP} 20-\mathrm{Au}_{4} \mathrm{Zr}$ & 12 & 12 \\
\hline \multirow[t]{2}{*}{$\mathrm{MAu}_{5}$} & $\mathrm{BaAu}_{5}, \mathrm{CsAu}_{5}, \mathrm{EuAu}_{5}, \mathrm{KAu}_{5}, \mathrm{RbAu}_{5}, \mathrm{SrAu}_{5}$ & hP6-CaCu & 18 & 12 \\
\hline & $\mathrm{CaAu}_{5}$ & $\mathrm{cF} 24-\mathrm{AuBe}_{5}$ & 16 & $12-16$ \\
\hline \multirow[t]{2}{*}{$\mathrm{MAu}_{6}$} & $\mathrm{RAu}_{6}(\mathrm{R}=\mathrm{Dy}, \mathrm{Gd}, \mathrm{Ho}, \mathrm{Sm}, \mathrm{Tb})$ & tP56-SmAu 6 & 16 & $13-14$ \\
\hline & $\mathrm{RAu}_{6}(\mathrm{R}=\mathrm{Ce}, \mathrm{Nd}, \mathrm{Pr})$ & $\mathrm{mC} 28-\mathrm{PrAu}_{6}$ & 18 & $13-14$ \\
\hline
\end{tabular}




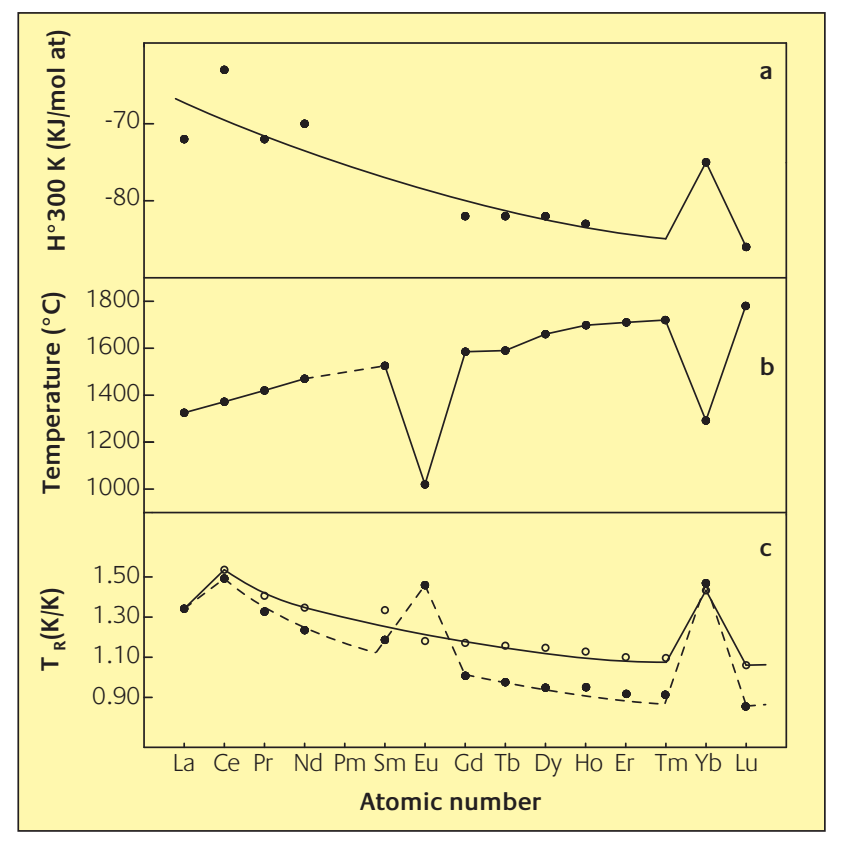

Figure 13

RAu compounds of gold with the rare earth metals. The trend of some typical parameters, and their correlation, is shown. In (a) the values of the enthalpy of formation are given; in (b) the melting points; in (c) the "reduced" melting temperatures $T_{R}$ (ratio between the compound melting temperature and the melting temperature of the rare earth metal involved, both in Kelvin degrees). In this last graph, the open symbols represent the experimental values which are higher than the reference ones (filled symbols) computed assuming a constant melting point through the rare earth series. All these data correspond to an increasing stability of the phase with the increase of the atomic number of the rare earth metal

\section{About the authors}

R. Ferro is Professor Emeritus, A. Saccone and S. Delfino are Full Professors and D. Macciò is Researcher at the Department of Chemistry of the University of Genova, Italy. They are interested in the physical and inorganic chemistry of alloys and are involved in phase diagrams determination, assessment and thermodynamic optimisation, alloy calorimetry and crystal chemistry of intermetallics.

\section{References}

1. W.S. Rapson, T. Groenewald, "Gold Usage”, Academic Press, London, 1978

2. L.S. Benner, T. Suzuki, K. Meguro and S. Tanaka (Eds.) "Precious Metals Science and Technology", The International Precious Metals Institute, Allentown, USA, 1991

3. H. Renner and M.W. Johns "Gold" in: "Handbook of Extractive Metallurgy”, F. Habashi (ed.), Wiley-VCH, Weinheim, 1997, vol. 3, pp. $1183-1213$
4. H. Okamoto and T.B. Massalski Eds., "Phase diagrams of binary gold alloys", ASM International, Metals Park, USA, 1987

5. A. Prince, G.V. Raynor and D.S. Evans "Phase diagrams of ternary gold alloys", The Institute of Metals, London, UK, 1990

6. T.B. Massalski, H. Okamoto, P.R. Subramanian, L. Kacprzak, (Eds): "Binary Alloys Phase Diagrams", 2nd edition, Vol.1, ASM International, USA, 1990

7. P. Villars, L.D. Calvert, H. Okamoto, "Handbook of Ternary Alloy Phase Diagrams”, Vol. 1-4, ASM International, USA, 1995

8. H. Okamoto, "Phase Diagrams for Binary Alloys", ASM International, Materials Park, USA, 2000

9. P. Villars, F. Hulliger, J. Less-Common Metals, 1987, 132, 289

10. P. Villars, K. Mathis, F. Hulliger in: "The Structures of Binary Compounds. Cohesion and Structure”, vol. 2. F.R. De Boer and D.G. Pettifor (Eds.), North Holland, Amsterdam, 1989

11. P. Villars, K. Cenzual, J. Daams, F. Hulliger, H. Okamoto, K. Osaki, A. Prince, S. Iwaka, "Pauling File. Inorganic Materials Data Base and Design Systems", Binaries Edition, 2002

12. E.T. Teatum, K.A. Gschneidner, Jr. and J.T. Waber, "Compilation of calculated data useful in predicting metallurgical behavior of the elements in binary alloy systems", Report LA-4003, UC-25, Metals, Ceramics and Materials, TID-4500, Los Alamos Scientific Laboratory, 1968

13. A. Saccone, D. Macciò, S. Delfino, R. Ferro, Metall. Mater. Transactions A, 1999, 30, 1169

14. A. Saccone, D. Macciò, S. Delfino, R. Ferro, Intermetallics, 2000, 8, 229

15. A. Saccone, D. Macciò, S. Delfino, R. Ferro, Intermetallics, 2002, 10, 903

16. R. Ferro, G. Borzone, N. Parodi, J. Alloys and Compounds, 2001, 321, 248

17. K.A. Gschneidner, Jr., J. Less-Common Metals, 1969, 17, 1

18. S. Delfino, A. Saccone, R. Ferro, J. Less-Common Metals, 1984, 102, 289

19. A. Saccone, S. Delfino, R. Ferro, J. Less-Common Metals, 1988, 143, 1

20. Y. Ning, Gold Bulletin, 2001, 34, 77

21. A.R. Miedema, J. Less-Common Metals, 1973, 32, 117

22. A.D. Pelton, "The Au-Cs (Gold-Cesium) system" in: "Phase diagrams of binary gold alloys" H. Okamoto and T.B. Massalski Eds., ASM International, Metals Park, USA, 1987, pp.72-76

23. G.V. Raynor, J. Less-Common Met., 1972, 29, 333

24. T.B. Massalski,"Structure and stability of alloys" in: "Physical Metallurgy", R.W. Cahn and P. Haasen Eds., North Holland, Amsterdam, 1996, vol. 1, pp. 135-204

25. G. Van Tendeloo and S. Amelinckx, Phys. Status Solidi A, 1981, 65, 73

26. G. Van Tendeloo and S. Amelinckx, Phys. Status Solidi A, 1981, 65, 431

27. K. Burkhardt and K. Schubert, Z. Metallkde., 1965, 56, 864

28. H. Okamoto, T.B. Massalski, D.J. Chakrabarti and D.E. Laughlin, "The AuCu (Gold-Copper) system" in: "Phase Diagrams of binary gold alloys" H. Okamoto and T.B. Massalski Eds., ASM International, Metals Park, USA, 1987, pp.76-95

29. R.W. Cahn, Nature, 1998, 396, 523 